\title{
A criação da galeria das travestis no presídio central de Porto Alegre: uma análise a partir dos tensionamentos entre estrutura e ação
}

The creation of the travestis gallery in presidio central de Porto Alegre: an analysis through the tensionings between structure and action

\section{Marcelli Cipriani}

Resumo O objeto deste artigo é a criação da galeria das travestis no Presídio Central de Porto Alegre, ocorrida no ano de 2012. Tem-se como objetivo analisar o espaço conhecido como " 3 a do H" a partir do tema da estrutura e da ação na teoria social contemporânea, conferindo-se ênfase às contribuições de dois autores que buscaram sintetizar essas dimensões do social: Anthony Giddens e Pierre Bourdieu. Os dados utilizados advêm da participação em duas pesquisas - a primeira, envolvendo as experiências de travestis com o sistema de segurança pública do estado do Rio Grande do Sul, e a segunda ocupada com a compreensão das relações de poder internas ao PCPA. Argumenta-se que a galeria resultou das práticas sociais de variados atores - que, de modos distintos, repercutiram em um mesmo resultado. Ademais, embora a galeria tenha flexibilizado as regras estruturais referentes à transfobia no espaço carcerário, tal mudança coexistiu com sua reprodução no universo prisional.

Palavras-chave Travestis. Presídio Central de Porto Alegre. Estrutura. Ação.

Abstract This article object is the creation of the travestis gallery in Presídio Central de Porto Alegre, occurred in 2012. Its objective is to analyze the space known as " 3 a do H" from the theme of structure and action in contemporary social theory, emphasizing the contributions of two authors who sought to synthesize these social dimensions: Anthony Giddens and Pierre Bourdieu. The data used come from the participation in two surveys - the first one, involving the experiences of travestis with the public security system of the state of Rio Grande do Sul, and the second one dealing with the comprehension of power relations in PCPA. It is argued that the gallery resulted from the social practices of various actors - who, in different ways, produced the same result. In addition, although the gallery has soften the structural rules regarding transphobia in the prison space, this change coexisted with its reproduction in prison universe.

Keywords Travestis. Presídio Central de Porto Alegre. Structure. Action.

a Mestre em Ciências Sociais pela Pontifícia Universidade Católica do Rio Grande do Sul (PUCRS). Bacharela em Direito pela mesma Universidade e bacharela em Ciências Sociais pela Universidade Federal do Rio Grande do Sul (UFRGS). 


\section{INTRODUÇÃO}

As prisões brasileiras vêm sendo historicamente atravessadas pelo descumprimento da lei, por parte do Estado, no que tange à garantia de direitos assegurados à população encarcerada. A precariedade nas condições de vida de pessoas presas passa, por exemplo, pela assistência material deficitária, pelas ínfimas oportunidades de trabalho e estudo, pela omissão na atenção à saúde dos custodiados e pela oferta insuficiente de assistência judiciária. Nesse sentido, as cifras destinadas ao investimento público no sistema carcerário, por vezes consideradas elevadas pela população, costumam antes expressar a demanda decorrente da manutenção do indivíduo preso do que da manutenção do preso enquanto pessoa (cf. GodoI, 2017).

Ademais, em inúmeras casas prisionais e durante diferentes momentos históricos, a tortura e os espancamentos foram recorrentemente empregados como punição a quaisquer descumprimentos das normas institucionais (GóEs, 2009). Para além da violência física diretamente cometida por agentes penitenciários, das agressões ou violações sexuais cometidas entre presos com respaldo de agentes estatais e dos massacres que os governantes argumentam escapar de seu controle ${ }^{1}$, outras manifestações de violência atravessam o cotidiano das prisões - de acordo com características mais amplas e estruturais que, no cárcere, adquirem formas próprias. Isso se percebe, por exemplo, no encontro do "dispositivo do aprisionamento" com o "dispositivo da sexualidade" (Foucault, 2011, p. 244-245).

Segundo Bourdieu (2010), o movimento gay e lésbico reúne indivíduos que, apesar de estigmatizados e sujeitos a inúmeras discriminações, não necessariamente estão expostos a handicaps econômicos e sociais. De modo geral, essa condição não se estende às travestis, cujas intersecções entre a classe e o gênero - não raro, também a etnia - colocam-nas entre os grupos mais desfavorecidos socialmente (CARrara; Vianna, 2006). Assim, de todas as identidades de gênero não hegemônicas, é provável que a travesti seja a mais vulnerável (SEFFnER; PAssos, 2016). Empurradas ao desemprego e à pobreza, e muitas vezes a atividades como a prostituição e o tráfico de drogas, elas também se tornam alvo visível do poder punitivo (PAssos, 2014).

Nos espaços prisionais masculinos - para onde, quando capturadas pelas malhas do sistema de justiça criminal, as travestis são direcionadas - prevalece

1 Recentemente, 55 presos foram assassinados em menos de 48 horas em presídios no Amazonas. O governador do estado, quando questionado sobre o episódio, afirmou que uma situação como essa seria praticamente impossível de impedir. A declaração pode ser acessada no seguinte endereço: https://exame.abril.com.br/brasil/e-praticamente-impossivel-impedir-diz-governador-do-am-apos-massacre/ 
um sistema de valores que associa a masculinidade ao poder. Essa condição resulta no estabelecimento de clivagens entre os presos tomados como homens e aqueles que podem ser considerados, por eles, como "não homens" (WELZER-LANG, 2001, p. 465) - o que faz com que os códigos de conduta da população encarcerada, dado que assentados sobre rígidos ideais de masculinidade, produzam categorias englobantes, que abarcam expressões como "homossexual, mona, bicha e viado" (ZAmboni, 2016, p. 16) (grifos no original). Com isso, repetindo a marginalização social, verifica-se a marginalização dessas pessoas no universo social da prisão (ZAMBOni, 2017).

O choque entre a identidade de gênero e o ambiente prisional amplifica as experiências de opressão que acompanham a vida das travestis, que passam a estar sujeitas a ainda maior precariedade do que o resto da população presa (SEFFNER; PAssos, 2016). De acordo com Ferreira (2018), a experiência das travestis no cárcere lhes expõe a padrões distintos de controle sobre seus corpos, até então não experimentados - e, apesar de as violências representarem um modo de funcionamento geral do sistema, elas chegam às travestis sob formas peculiares, sendo agravadas em decorrência de suas identidades de gênero (FERrEIRA, 2015).

No Presídio Central de Porto Alegre (PCPA), maior estabelecimento prisional do estado do Rio Grande do Sul, os abusos vividos por travestis encarceradas costumavam, até recentemente, se expressar em termos multidimensionais - da violência física e sexual ao campo simbólico, sendo promovidas tanto pelos demais presos, quanto pelos policiais militares que administram o Central desde 1995 . Esse contexto começou a mudar no ano de 2012, quando foi estabelecida a " 3 a do H" $-3^{\text {a }}$ galeria do anexo $\mathrm{H}$ do prédio - onde as travestis encaminhadas para o PCPA, assim como os presos homossexuais com quem elas nutrissem relações afetivas, passaram a viver. Antes da inauguração da galeria ${ }^{2}$ específica, elas costumavam ser direcionadas aos espaços em que estavam os duques ou presos do artigo termos que denotam os indivíduos cumprindo pena por crimes sexuais - o que lhes acarretava inúmeros sofrimentos.

O objetivo desse artigo é analisar a criação da " 3 a do H" a partir do tema da estrutura e da ação na teoria social contemporânea, conferindo-se ênfase às contribuições de dois autores que buscaram sintetizar essas dimensões do social: Anthony Giddens e Pierre Bourdieu. Sob esse pano de fundo, se irá refletir acerca de como algumas das estruturas que informam a prisão - com foco nas regras sociais referentes ao machismo e à transfobia coletiva e institucional, que vinham

2 O PCPA é dividido em pavilhões, e cada um de seus andares equivale a uma galeria. 
orientando o tratamento feito pelos agentes estatais e pela população encarcerada às travestis presas - interagiram com a expressão da agência de diferentes atores inseridos nesse período histórico, repercutindo no surgimento da galeria.

Argumenta-se, ao longo do texto, que a criação da galeria resultou de uma conjunção de ações, imbricando a intensa mobilização das travestis presas com a atuação de organizações de direitos de travestis e de mulheres transexuais. Ainda, que se deu pela convergência entre a existência de um espaço exclusivo às travestis e os interesses dos gestores do Central. Ademais, destaca-se que também havia o estabelecimento de uma conjuntura política favorável no âmbito do Governo Estadual, que então passava a intensificar as políticas públicas de gênero e de identidade. Nas considerações finais e como saldo dos diferentes sentidos que as ações dos agentes assumiram nas estruturas, são apontadas transformações e permanências nas regras sociais que pautavam as relações no Central.

Os dados utilizados neste trabalho advêm de duas experiências empíricas. Primeiro, da participação em um projeto, entre os anos de 2013 e 2014, sobre a experiência social de travestis e transexuais com o sistema de segurança pública, em que foram aplicadas entrevistas com travestis e mulheres transexuais, além de com gestores e técnicos da segurança pública gaúcha. Tais informações, publicizadas em artigos acadêmicos, são devidamente referenciadas quando utilizadas no texto. Os dados também são fruto de outra pesquisa ${ }^{3}$, desenvolvida entre $2016 \mathrm{e}$ 2018, que visou a compreender as relações de poder internas ao PCPA - contando, para isso, com a aplicação de entrevistas com presos, policiais militares em ofício no estabelecimento e com atores do sistema de justiça ocupados com a execução criminal. Ainda, com a sistematização de conversas informais feitas com outros custodiados - incluindo-se travestis da " 3 a do H" - psicólogos e assistentes sociais funcionários da prisão.

\section{TRAVESTILIDADES, VIOLÊNCIAS E SISTEMA DE JUSTIÇA CRIMINAL}

Nas duas últimas décadas, as ciências sociais brasileiras vêm vivenciando um adensamento de estudos cujo foco é a prisão, o que aponta para uma consolidação desse campo de pesquisas (GodoI, 2017). De acordo com Lourenço \& Alvarez (2018), em texto ocupado com um balanço de tal produção, 25\% dos trabalhos dizem respeito ao confinamento de mulheres. Apesar dos autores não tenham levantado informações sobre investigações centradas na população LGBT, seus

3 A pesquisa resultou na dissertação intitulada "Os coletivos criminais de Porto Alegre entre a 'paz' na prisão e a guerra na rua” (CIPRIANI, 2019). 
achados indicam o aumento da importância que a categoria analítica gênero vem adquirindo nas universidades - tendência também observada nas pautas de movimentos sociais, na imprensa e na produção cultural.

Consoante Lago \& Zamboni (2016), para além do crescimento absoluto do número de mulheres cisgênero, transgênero e travestis presas, não só essas populações têm se tornado mais visíveis na esfera pública, como também as questões de gênero e sexualidade em contextos de privação de liberdade estão adquirindo progressiva visibilidade. Esse recente descortinamento é acompanhado do incremento exponencial da população encarcerada no Brasil: entre os anos 2000 e 2016, o total de pessoas privadas de liberdade passou de pouco mais de 230 mil para 726 mil (BRASIL, 2017a) ${ }^{4}$. Caso esses dados sejam avaliados a partir de marcadores de gênero, pode-se perceber que, durante o mesmo período, a população prisional masculina teve aumento de 293\%, enquanto a feminina subiu 656\% (BRASIL, 2017b).

O encarceramento galopante verificado pelos índices correlacionados resulta, em grande medida, da política de drogas adotada no país - que, desde a década de 70, toma o discurso de "guerra às drogas" como referência para o aprisionamento em massa. Entretanto, seus efeitos para o controle social adquiriram proporções ainda mais críticas recentemente - primeiro, com a aplicação da lei de crimes hediondos nos anos 1990, equiparando o tráfico de drogas como tal e, especialmente, com a aprovação da nova lei de drogas, sancionada em 2006.

Alegadamente motivada pela prevenção do consumo e pela necessidade de deslocar usuários de psicotrópicos do sistema de justiça criminal para o sistema de saúde, na prática a nova lei apropriou-se do paradigma de redução de danos para aumentar a pena para o tráfico e manter a criminalização do porte para o uso. Com isso, o dispositivo tem colaborado diretamente com o aumento do aprisionamento por motivo de drogas, tanto por reafirmar a indistinção entre usuário e traficante (que depende da discricionariedade da classificação policial), quanto por rejeitar a alternativa médica que lhe serviu de inspiração (CAMPOS, 2015).

Em tal contexto, os impactos para a população feminina foram ainda mais expressivos do que para a masculina: no ano de 2016, 26\% dos homens presos no Brasil haviam sido condenados ou aguardavam julgamento em decorrência do

4 Em relação ao contingente populacional, essa mudança implica que a taxa de aprisionamento no país cresceu $157 \%$. De acordo com o levantamento nacional de informações penitenciárias, no ano 2000 existiam 137 pessoas presas para cada grupo de 100 mil habitantes. Em 2016, por sua vez, essa taxa havia subido para 352,6 pessoas presas para cada 100 mil habitantes (cf. BrasiL, 2017a).

5 O total de homens privados de liberdade passou de 169 mil para 665 mil entre os anos 2000 e 2016, enquanto a população de mulheres encarceradas foi de menos de 6 mil para mais de 42 mil (cf. BrasiL, 2017b). 
tráfico de entorpecentes. Quanto às mulheres presas, esse percentual atingia $62 \%$ (BRASIL, 2017a). No que tange aos LGBT, inexistem dados oficiais concernentes ao sistema prisional - não há, portanto, apuração acerca de quantos homossexuais, lésbicas, transexuais e travestis estão presos, o que repercute na dificuldade de elaboração de políticas públicas específicas e deixa implícita a falta de comprometimento estatal com essa população.

Apesar da ausência de informações concretas, as pesquisas de Ferreira (2015) e Galli (2013) sobre o contexto do Rio Grande do Sul indicam que a maioria das travestis presas no estado haviam sido acusadas por tráfico de drogas. Nesse sentido, Lago \& Zamboni (2016) argumentam que a criminalização de um grande número de mulheres próximas às franjas do tráfico se estendeu a muitas travestis que trabalham no contexto da prostituição ou vivem em situação de rua - que, para viabilizarem a atividade profissional, financiarem o uso de substâncias, pagarem dívidas ou complementarem a renda, se envolvem com o comércio de drogas de pequena monta (FERrEIRA, 2018). Serra (2018), por sua vez, destaca que tais elementos - mercado sexual e mercado ilícito de drogas - estão imbuídos de arranjos geopolíticos que aprofundam a vulnerabilidade das travestis diante do sistema de justiça criminal.

Cabe ressaltar que o aprisionamento é apenas uma de múltiplas dimensões da violência a que as travestis estão recorrentemente sujeitas. Kulick (2008, p. 47) chega a declarar que "em nenhum outro lugar a violência é tão ubíqua quanto no cotidiano das travestis", se tratando do "eterno pano de fundo de suas vidas". A afirmação do autor perpassa pelo fato de que essas pessoas se veem obrigadas a reafirmar, a cada instante, a simples prerrogativa de ocupação do espaço público, podendo a qualquer tempo se tornarem alvos de agressões verbais ou físicas cometidas por aqueles que se sentem ofendidos por sua mera presença nesse espaço.

A exposição noturna das travestis - em decorrência da prostituição, alternativa de subsistência para parte substancial dessa população - as coloca em posição ainda mais crítica, tornando-as um alvo fácil do assédio verbal e dos espancamentos. De acordo com Kulick (2008, p. 47), que desenvolveu pesquisa com um grupo de travestis em Salvador, era comum "ver gente que passa de carro lançar pedras e garrafas sobre elas", algumas vezes chegando a "disparar armas de fogo contra travestis em plena rua”. Carrara \& Vianna (2006), por sua vez, demonstram a particular vulnerabilidade das travestis aos crimes de execução, de modo geral seguidos por baixos índices de resolução. Na imprensa, esses casos costumam obliterar a responsabilidade dos autores das violências, mantendo-a em segundo 
plano ou transferindo-a para as armas utilizadas - como se os objetos fossem os causadores dos delitos (Kulick, 2008).

A despeito da sujeição aos crimes violentos, é sobre as travestis que recai o estereótipo da periculosidade e da criminalidade - com a sexualidade e a violência constituindo-se reciprocamente (BARRETO, 2017). Nas páginas policiais, quando não figuram como cadáveres, elas são trazidas como perigosos marginais - cuja afeição ao crime, a perversão e o vínculo quase necessário com a perturbação da ordem e o caos repetem-se como representação coletiva (CARRARA; VIANNA, 2006; Kulick, 2008; Ferreira, 2018; SERrA, 2018). De um lado, essas construções sociais alimentam a perseguição institucional, tornando-as vulneráveis à brutalidade policial (KuLICK, 2008). De outro, a criminalização abstrata e generalizada da categoria travesti chega até os tribunais, na medida em que a própria travestilidade é mobilizada pelo sistema de justiça como um sinal de periculosidade - com as travestis sendo tratadas não só como possíveis criminosas, mas como prováveis criminosas (SERRA, 2018).

Então, quando as travestis são efetivamente capturadas pelo dispositivo do aprisionamento, o dispositivo da sexualidade também é acionado, e o estigma da criminalização ganha relevância: aquilo que, até então, era motivo de suspeita passa a ser confirmado mediante o seu ingresso na prisão, "e a ideia de 'sexualidade marginal' é ratificada como verdadeira, recebendo materialidade" (FERREIRA, 2015, p. 124). As sexualidades e gêneros considerados dissidentes, portanto, seriam algumas das determinantes que provocariam a seleção de certos indivíduos para o aprisionamento, sobretudo quando interseccionalizadas com outros elementos que repercutem em vulnerabilidades sociais e ao sistema penal (FERREIRA, 2014).

\section{TEORIAS DE SÍNTESE ENTRE A AÇÃO E A ESTRUTURA E FERRAMENTAS PARA PENSAR O UNIVERSO SOCIAL DA PRISÃO}

Após a Segunda Guerra Mundial e sob a influência do estrutural-funcionalismo, a teoria social atravessou um amplo consenso a respeito de sua natureza e de suas tarefas (GidDEns, 2013). Buscando acabar com o conflito que, outrora, assolava a sociologia, Talcott Parsons havia tentado compatibilizar a ação voluntária e a determinação estrutural em uma mesma teoria sobre o indivíduo. Todavia, a partir do final da década de 60 e em reação ao paradigma partilhado no pós-guerra, surgiram inúmeras escolas de microteorização e de macroteorização - que, consolidando o discurso sobre a ação versus a estrutura, acentuavam a centralidade de uma ou de outra dessas dimensões na determinação dos comportamentos (ALEXANDER, 1987). 
Assim, na "irremediável desordem" de vozes teóricas rivais - que tomaram o terreno antes ocupado pelo "consenso ortodoxo" parsoniano - havia posições marcadamente coletivistas e individualistas (GIDDENs, 2013). Enquanto as primeiras consideravam os padrões sociais preexistentes aos atos individuais, com a ordem social se impondo aos atores de fora, as segundas os defendiam como resultado da negociação individual. Porém, a vitalidade de ambas as posições durou pouco: em meados dos anos 80, a fase criativa dos movimentos já chegava ao fim e, em seu lugar, emergia um renovado discurso, marcado pelo retorno à junção das teorias sobre a ação e a estrutura (AlEXANDER, 1987).

De acordo com Ortner (2006), o desafio de superar a oposição entre ação e estrutura foi definitivamente assumido pelos autores da "teoria da prática". Tratando do mesmo período histórico e de iguais pretensões, Alexander (1987) classificou-os como integrantes de um "novo movimento teórico". Esses intelectuais expressaram suas tentativas de síntese de modos variados - e, em comum, devolveram o ator ao processo social sem ignorar as estruturas mais amplas que exercem coerção sobre a ação, mas também a possibilita (ORTNER, 2006). Dois sociólogos são referidos tanto por Alexander (1987) quanto por Ortner (2006) e, por isso, serão privilegiados na presente análise: Anthony Giddens e Pierre Bourdieu.

Para Bourdieu (2015, p. 355), o encontro entre a ação e a estrutura foi especialmente manifesto por meio do conceito de habitus - um elemento inconsciente, fruto da interiorização das estruturas sociais. O habitus é traduzido nos esquemas de pensamento, de ação e de percepção que o ator possui por pertencer a uma sociedade, a uma época e a uma classe - e que, ao mesmo tempo, são aplicados a situações particulares, orientando seus atos de criação como uma "gramática geradora de condutas”. A relação dialética entre a ação e a estrutura proposta pelo autor seguiu, entretanto, bastante influenciada pelo funcionalismo - posto que, no processo de "internalização da externalidade e externalização da internalidade" (BouRdieu, 2013, p. 72), o ator corresponde a uma variante estrutural, e ainda que seus atos digam respeito a uma improvisação, ela se dá sob um repertório relativamente dado, tendendo à reprodução cíclica.

Por sua vez, com o mesmo objetivo de articular a estrutura com a ação, Giddens (2013) operou a partir da noção da "dualidade da estrutura" - tomando a estrutura como o meio e o resultado da conduta que ela recursivamente organiza. Em desacordo com os funcionalistas clássicos, na perspectiva giddensiana a estrutura não diz respeito à padronização das relações ou dos fenômenos sociais - a isso, o autor chama de sistema -, mas aos conjuntos de regras (normativas e de significação) e de recursos que são recursivamente utilizados pelos atores quando na reprodução 
da ação, estando implicados em suas práticas. Daí é que a durabilidade de tais padrões no prolongamento do tempo e do espaço - sua institucionalização - não é inevitável, pois eles só se mantêm enquanto seguirem sendo reproduzidos pelos agentes. Portanto, as propriedades estruturais identificadas em sistemas sociais não existem fora da ação, mas "estão cronicamente envolvidas em sua produção e reprodução" (GIDDENS, 2013, p. 441).

As contribuições de Giddens e Bourdieu têm claras aproximações: para além do exercício de síntese que desempenham, a produção e a reprodução social são pensadas, em ambos, a partir da noção de regras (sociais ou do campo) e de recursos (alocativos e autoritativos ou formas de capital). Todavia, em comparação com Bourdieu (2013), a teoria da estruturação de Giddens (2013, p. 17) confere maior atenção à agência, que é entendida como a capacidade do ator de intervir ou não no mundo, podendo "influenciar um processo ou um estado específico de coisas". O conceito está intimamente relacionado à sua noção do poder - que flui por meio dos recursos empregados pelos indivíduos (constituintes das estruturas) na reprodução da ação. À semelhança de Foucault (2011), Giddens (2013) toma o poder não só como uma relação negativa, mas produtiva. Entretanto, é um crítico da ideia de "corpos dóceis", destacando que o poder pressupõe relações regularizadas de autonomia e dependência, que são sempre de mão dupla.

No âmbito do sistema prisional, as contribuições referidas - a despeito de suas diferenças quanto ao peso conferido às tradições objetivistas e subjetivistas da vida social - abrem espaço para inúmeras reflexões. Inicialmente, permitem pensar a transfobia que vigora no ambiente carcerário como uma versão de traços estruturalmente incorporados pelos atores, seja devido à internalização que conforma "esquemas fundamentais, previamente assimilados" (Bourdieu, 2015, p. 349), seja como regras semânticas associadas à atribuição de significados e constituintes de uma consciência prática que, nas interações prisionais cotidianas, permite aos indivíduos saberem "como prosseguir" (GidDENs, 2013, p. 27).

No "mundo do crime", entendido como um espaço de representações e elaboração de visões de mundo (RAmalHo, 2008), o "ethos da masculinidade" (ZaLUAR, 1996, p. 110) é um balizador das relações sociais, sendo amplamente reproduzido e, com isso, adquirindo caráter rotinizado - para usar os termos de Giddens (1979). Nesse sentido, as prisões são análogas ao "mundo do crime”, pois são fundamentalmente lugares "para homens heterossexuais" - onde ocorre a naturalização de um padrão masculino e heterossexual que implica a produção de "outros" marcados em termos de gênero e sexualidade (LAGo; Zamboni, 2016). Assim, o machismo e a transfobia que integram o "sistema de disposições duráveis" dos atores também está 
relacionado às condições materiais de existência que dizem respeito "às estruturas constitutivas de um particular tipo de ambiente" (Bourdieu, 2013, p. 72) - que, aqui, é pensado a partir das regras que informam a vida na prisão.

Giddens (2013) ressalta que o espaço não é, meramente, um local onde se dá a atividade social, mas que influi na composição das interações entre os atores, estando implicado no formato assumido por suas práticas. Por isso, a compreensão sobre a ação social na prisão não pode ser afastada do próprio substrato carcerário, cujas características tanto impactam a manifestação de regras estruturais - por exemplo, aprofundando os padrões de masculinidade - como também influenciam o contingente de recursos disponíveis ao exercício da agência. Não é coincidência que, em alternativa à ausência de mecanismos reivindicatórios capazes de canalizar o descontentamento da população penitenciária, os presos muitas vezes recorram ao uso da violência física para efetuar pressão em agentes penitenciários (GóEs, 2009).

Inseridos nos feixes de interações firmadas na prisão, como demarcado por Giddens (2013), os presos não são apenas corpos dotados de uma mobilidade restrita, mas seres intencionais, com aptidão para influenciarem cursos de ação. Para realizarem suas capacidades de agência, eles têm de lançar mão de recursos limitados com vistas a superarem as restrições com que se defrontam, o que incita o estabelecimento de relações sociais. De outro lado, os atores estatais que administram a prisão - ainda que assumindo posições de autoridade - precisam contar com os presos para o desempenho de atividades diversas, a fim de viabilizarem o funcionamento do sistema prisional em face da existência de outras propriedades estruturais que o constitui (como as condições incitadas pela superlotação, pelo baixo investimento e contingente de agentes).

No Brasil contemporâneo, em que as prisões operam de forma cronicamente superlotada e sob condições materiais absolutamente precárias, as noções de Sykes (1958) sobre os "defeitos do poder total" e a necessidade de cooperação ativa dos custodiados para a manutenção da ordem no cárcere adquirem outra dimensão - e não raro os presos são inseridos nas próprias engrenagens do sistema, que depende deles para seguir operando. Assim, a prisão não é um mero depósito incapacitante, mas promove, a todo momento, a mobilização dos custodiados - por exemplo, com os agentes transferindo-lhes a responsabilidade pelo andamento de seus processos (GoDoI, 2017), ou por atividades elementares como a distribuição de bens, o encaminhamento de internos para fins de atendimentos e audiências judiciais e a própria manutenção da “paz” (CIPRIANI, 2019). 
Essas dinâmicas em muito se assemelham com a noção de dialética do controle trazida por Giddens (2013), que afirma que os menos poderosos sempre, em algum nível, são capazes de administrar recursos de modo a conseguirem exercer o controle sobre os mais poderosos em relações estabelecidas de poder. As considerações do autor acerca do poder não são, como trazido, idênticas às de Bourdieu (2013), para quem o poder estrutural assume maior relevância do que o expresso nas práticas. Segundo ele, o habitus se encontra tão profundamente mergulhado nas pessoas "que elas acabam amoldando-se sem que ninguém as faça agir assim” (ORTner, 2006, p. 24). Para Bourdieu (2010), o peso das estruturas é forte a ponto de mesmo aqueles prejudicados por elas terminarem por reproduzi-las, assumindo a respeito de si o ponto de vista dos dominantes. É o que o autor chama de dominação ou violência simbólica.

Apesar dos diferentes pesos que atribuem às estruturas ou às ações sociais, tanto Bourdieu quanto Giddens - autores da "teoria da prática" (ORTNER, 2006) e que integraram o "novo movimento teórico" (AlEXANDER, 1987) - auxiliam na análise do universo social do PCPA no que toca à criação da " 3 a do H". Neste artigo, de um lado, se argumentará que o "caráter bilateral do aspecto distributivo do poder" (GIDDENs, 2013, p. 441) se encontra na base da criação da " 3 a do H" - na medida em que a galeria resultou, em parte relevante, da eficaz administração de recursos feita pelas travestis no PCPA em interação com agentes estatais. De outro, que as dinâmicas internas da galeria seguiram permeadas por disposições estruturais antes observadas - manifestas pelas próprias travestis, que continuaram reproduzindo a violência simbólica (cf. BOURDIEU, 2010) a partir da legitimação de regras de conduta e de convivência pautadas em padrões normativos de gênero (FERrEIRA, 2015).

Essas questões remetem tanto à ideia de que a dialética da prática perpassa pela adoção (consciente ou não) de estratégias orientadas ao alcance de interesses simbólicos e materiais, com as estruturas permanecendo enquanto são capazes de satisfazê-los (Bourdieu, 2013), quanto ao argumento de que a mudança e a reprodução social fazem parte de toda ação (GIDDENs, 1979) - portanto, que mesmo diante de grandes transformações, identificam-se permanências. Desde esse ponto de vista, Bourdieu e Giddens dialogam e conferem subsídios para a consideração de outro fator - sistêmico - que exerceu influência no surgimento da " 3 a do H": o momento histórico, que também será abordado na análise feita a seguir.

\section{A TRANSFOBIA COMO REGRA ESTRUTURAL NO PCPA}

Até o ano de 2012, as travestis que acessavam o Presídio Central de Porto Alegre eram encaminhadas às mesmas galerias atribuídas aos duques ou presos do 
artigo - acusados por crimes sexuais - e que, como elas, sofrem enorme repúdio do resto da população encarcerada. Segundo Ferreira (2015, p. 111), o critério de distribuição dizia respeito ao desejo de aglomerar, em um só local, todos os tipos “indesejáveis dentro dos já segregados" - o que representaria uma concepção das travestis como parte do que coletivamente se entende como desvio sexual, mesmo que seus delitos não fossem da ordem sexual.

Tal espacialização expunha as travestis a inúmeras formas de violência. Galli (2013), por exemplo, relata o caso de uma custodiada que, apenas durante a primeira noite do cumprimento de sua pena, foi vendida cinco vezes, de um preso a outro, servindo de objeto sexual de quem a possuía. Para além das "trocas" de travestis por maços de cigarros, dinheiro e televisores - dentre outros - e dos recorrentes estupros, elas costumavam ser usadas como "mulas" para o tráfico de ilícitos e para o ocultamento das drogas durante batidas policiais (FERREIRA, 2015). Portanto, tinham os corpos instrumentalizados como recursos, acionados por outros presos a fim de reproduzirem certas práticas ${ }^{6}$. Ademais, sua mercantilização reiterada também atualizava as disposições estruturadas (BouRdiEu, 2013) que os presos nutriam quanto às relações de gênero, acirradas na prisão.

Outras violências, calcadas no estabelecimento de fronteiras sociais entre travestis, homossexuais e demais custodiados pautavam as normas de convivência: para que relações afetivas se concretizassem, elas deviam passar pelo crivo dos prefeitos - os representantes de cada galeria, que assumem uma posição de poder na prisão e efetuam a mediação entre os presos e os agentes estatais - os quais decidiam sobre a possibilidade dos "casamentos" entre elas e seus companheiros. Em que pese esses rituais pudessem conceder visibilidade a relações não normativas no cárcere, tencionando as estruturas que informam a masculinidade prisional, eles eram articulados de forma a reforçá-las. Os "casamentos" perpassavam pela exotização dos casais, que tinham de se dirigir para um pátio do presídio e, na frente dos demais presos, se beijarem sob suas zombarias e deboches (AGuInsky; FERreira; Cipriani, 2013).

Após a relação firmada entre um homem cisgênero e uma travesti, ela não estava mais autorizada a conversar ou a se dirigir a outro homem. Se tornava a

6 Segundo Giddens (2013), os recursos que, juntamente às regras, constituem as estruturas sociais podem ser autoritativos (controle de pessoas) ou alocativos (controle de objetos materiais). É nesse sentido que, para o autor, as propriedades estruturais dos sistemas sociais expressam formas de dominação e poder. No cenário apresentado, a transfobia como regra social - padrão de interação - era manifesto, dentre outras formas, pelo uso dos corpos das travestis como recurso, através do qual os presos alcançavam interesses concretos e, ao mesmo tempo, fluía os diferenciais de poder assentados no gênero. 
"bicha” de seu marido, devendo tê-lo como acompanhante caso quisesse ir ao pátio ou mesmo caminhar nos corredores da galeria. Em seu turno, após o compromisso firmado com a travesti, os canecos, cigarros e talheres usados pela coletividade já não eram partilhados com seu marido, cuja existência se tornava maculada pelo nojo e pela repulsa nutridos por outros apenados (Aguinsky; FERreira; Cipriani, 2013). Assim, a transfobia e o machismo, disposições estruturantes no âmbito da sociedade mais ampla, compunham as matrizes de regras sociais que conformavam e regulavam as atividades nas galerias, conferindo certas significações às ações dos presos e sujeitando-as a uma gama de sanções específicas, aplicáveis àquele universo.

No âmbito das práticas de policiais ocupados com a administração prisional, a violência de gênero também era incorporada como propriedade estrutural 7 do sistema: antes da criação da galeria específica, às travestis costumavam ser imputadas penalidades como a raspagem de seus cabelos e a proibição de se vestirem segundo suas identidades de gênero, o que se somava ao uso reiterado de seus nomes de registro e com abusos físicos (Aguinsky; Ferreira; Cipriani, 2013). Em tal sentido, se manifestava como uma opressão calcada na invisibilização - que, apesar de lançar mão de signos visíveis nos corpos das travestis, cuja expressão de gênero não pode ser ocultada e se inscreve concretamente, se assentava na "negação de sua existência pública” (Bourdieu, 2010, p. 144).

Tendo em vista todos esses elementos, que perpassaram a história do Central durante mais de uma década, chega a soar irreal que a " 3 a do $\mathrm{H}$ " tenha sido efetivamente criada. Conforme trazido, a violência transfóbica expressa nas práticas dos presos era naturalizada, e mesmo as travestis engajavam-se em relações afetivas com fortes implicações para a sua já reduzida autonomia, bem como se expunham a rituais degradantes que atualizavam sua posição inferior nas hierarquias prisionais. Paralelamente, os policiais militares não faziam nenhuma questão de esconder o teor dos "esquemas fundamentais" que engendravam "esquemas particulares" (Bourdieu, 2015, p. 349) diretamente aplicados às situações que envolviam as travestis no cárcere. Ainda, os representantes do executivo estatal seguiram, sob diferentes gestões, inertes à situação - em que pese já existissem, ao menos desde os anos 90, comissões e órgãos responsáveis pela fiscalização das condições prisionais no estado.

7 De acordo com Giddens (2013), propriedades estruturais são as características estruturadas dos sistemas sociais - ou seja, se tratam de práticas institucionalizadas, que se estendem ao longo do tempo e do espaço. 
Mesmo assim, a " 3 a do H" foi instaurada em 2012 e, a partir de então, passou a ser tomada como algo que só trouxe "o bem e o bom” (FERreira, 2015, p. 115). Como decorrência disso, inúmeros atores sociais - travestis presas ou integrantes do movimento social, funcionários do Central e do Governo Estadual - começaram a disputar o protagonismo por sua criação, o que também perpassou por tentativas de instrumentalizar sua mobilização.

\section{A $3^{\text {A }}$ DO H: INSTRUMENTALIZAÇÕES, DISPUTAS DE PROTAGONISMO E SENTIDOS DA AÇÃO NAS ESTRUTURAS}

A passagem da administração do Central para a Polícia Militar (PM) em 1995 se deu no contexto de uma grave crise do sistema penitenciário gaúcho, marcada por recorrentes motins, rebeliões, fugas e tentativas de fuga em massa, bem como pelos altos índices de assassinato no cárcere. Em sua origem, a medida deveria durar até seis meses, prorrogáveis por mais seis - que seriam suficientes para que os policiais reestabelecem a "ordem" na prisão. Todavia, o prazo vem sendo renovado, a cada semestre, ao longo dos últimos 24 anos - em especial, pela aparente eficácia alcançada pela PM, posto que as mortes, fugas e demais turbulências caíram consideravelmente desde então e vêm se mantendo em níveis reduzidos.

Uma das principais táticas utilizadas pelos policiais para controlar as "turbulências" que se generalizavam no PCPA foi a espacialização estratégica dos apenados, que até então eram dispostos nas galerias desconsiderando-se as afinidades ou inimizades que nutriam entre si. Como os presos que não tinham compatibilidade eram colocados nos mesmos espaços - reduzidos, precários e superlotados - seus enfrentamentos eram rotineiros, o que provocava instabilidades consideráveis. A separação, feita a partir de variados critérios, contribuiu consideravelmente com a melhora na situação do Central, impactando a redução das violências internas. Ademais, ela foi aliada a uma forma de administração que estabelece canais de comunicação entre os policiais e os presos, por intermédio da figura dos prefeitos. Com isso, conflitos, problemas e insatisfações advindas de ambos os lados das grades das galerias passaram a ser encaminhados, evitando-se que adquirissem dimensões mais expressivas.

Nos anos 2000, grande parte das galerias do Central já se encontrava sob controle de diferentes coletivos criminais e, atualmente, também há aquelas destinadas aos apenados em programa de desintoxicação de entorpecentes, aos que desempenham algum tipo de serviço no PCPA (os trabalhadores), aos religiosos (evangélicos), aos presos por crimes sexuais, aos presos pela Lei Maria da Penha e aos ex-integrantes do sistema de segurança pública. A partir de 2012, a galeria 
voltada às travestis e aos seus companheiros homossexuais foi agregada a esse conjunto, também servindo como categoria de espacialização do presídio e como mecanismo da manutenção da "paz" e da "ordem".

Essa forma de distribuição dos corpos, que já se tornou institucionalizada, se dá a partir de negociações constantes entre apenados e policiais, nas quais enquanto esses concedem autonomia à população encarcerada para a gestão de suas galerias, aqueles se comprometem a não gerar tumultos, a não promover violência física entre si e nem com funcionários. Em suma, não podem causar problemas que "aparecem na televisão" (CIPRIANI, 2019. p. 99) e que prejudiquem a imagem do Central. Paralelamente, já que os agentes do Estado não entram na maioria das galerias - pois, devido aos graves problemas de superlotação, as celas se encontram permanentemente abertas, com os presos podendo transitar pelo espaço - é necessário contar com os custodiados para distribuírem a comida, efetuarem reparos internos, organizarem a alocação dos presos nas celas ou corredores e encaminharem os moradores à boca da galeria diante de solicitações da polícia, de atendimentos feitos na prisão e de audiências judiciais.

Assim, a criação da " 3 a do H" não foi um evento absolutamente inovador, e o estabelecimento de uma nova categoria de separação entre os presos não se tratou de uma transformação radical na gestão, mas do prolongamento de um mecanismo já integrado à administração do presídio. Por isso, pode-se afirmar que as próprias "normas de funcionamento institucional produziram subsídios para a emergência da galeria" (SEFFner; PASsos, 2016, p. 150), que não foi fruto do rompimento com uma condição anterior. Houve, todavia, algo de novo - na medida em que, a partir de determinado momento, a tática foi estendida para uma população até então ignorada, cujos sofrimentos reiterados vinham sendo reproduzidos desde muito antes.

Em parte, foi o caldo de relações sociais conformando essas regras estruturais, e radicalizando a transfobia existente além-muros, que deram ensejo à criação da galeria. Por um lado, uma nova geração de presas, mais disposta a confrontar as “categorias de percepção e avaliação" dos dominantes (BouRdiEU, 2010, p. 144), foi capaz de se articular para fazer pressão coletiva nos agentes estatais - inclusive promovendo instabilidades. Suas reivindicações forçaram uma flexibilização das estruturas, que resultou na introdução de novos atores sociais nas dinâmicas prisionais - capazes de servir, a partir de então, como recurso nas assimétricas relações de poder. Se tratava da ONG Igualdade/RS, parte do movimento de travestis e transexuais de Porto Alegre, que foi convidada pela direção do Central, em 2011, para oferecer uma oficina às travestis presas - presença que, mais tarde, se tornou permanente, com visitas mensais. 
A iniciativa, já uma vitória parcial da luta das travestis, também expunha a dificuldade de os funcionários lidarem com as demandas de uma população cujas particularidades não eram capazes de compreender - posto que, não raro, essas pessoas "parecem ser meras falhas do desenvolvimento ou impossibilidades lógicas, precisamente por não se conformarem às normas da inteligibilidade cultural" (ButLER, 2017, p. 44). Consoante demarcado, essa é uma forma de atribuir significado que, sob diferentes gradações, atravessa a sociedade como um todo, dado que a transfobia informa esquemas coletivamente interiorizados que não se restringem à prisão - embora, nela, essa violência assuma outros contornos.

Para chegar-se a isso, entretanto, foi necessário que as travestis presas se mobilizassem a ponto de provocar uma inflexão - o que se deu a partir de certa compreensão, ainda que incorporada na consciência prática, sobre a dialética do controle ${ }^{8}$. Na esteira da abordagem de Giddens (1979), o sistema prisional não trabalha "pelas costas" dos atores sociais que o cria e recria. As dinâmicas prisionais resultam de um conjunto de operações em que os agentes lançam mão de regras sociais que orientam suas práticas - às quais, apesar de não necessariamente terem instituído, contribuem recorrentemente para reproduzir e, com isso, também readequar. Conforme anteriormente referido, os presos são partes integrantes das engrenagens do sistema, e o conhecimento dessas regras enseja a possibilidade de acordos, tácitos ou explícitos, no âmbito da ambivalência presente em todas as relações de dominação.

É em tal sentido que, apesar da histórica transfobia incorporada nas práticas da polícia no Central, a criação da galeria torna-se coerente como um ato da instituição. A chamada da ONG à prisão e a criação da " 3 a do H" iam ao encontro do que vem sendo, desde que a PM assumiu o controle do PCPA, seu objetivo primeiro: a manutenção da "ordem" e a pacificação interna, com fins de manter um presídio superlotado e sob péssimas condições de sobrevivência "silencioso" - em que, para os policiais que administram o estabelecimento, "a melhor notícia [...] é não ser notícia” (CIPRIANI, 2019, p. 119). Não sabendo lidar com as reivindicações das travestis, que passaram a prejudicar a estabilidade prisional, a abertura à presença da Igualdade aprofundou ainda mais a flexibilização das estruturas,

8 Segundo Giddens (2013), a consciência prática diz respeito a todas as coisas que os agentes conhecem tacitamente sobre como "continuar" ou "prosseguir" nos contextos da vida social, sem que sejam capazes de lhes dar uma expressão discursiva direta. É, assim, o saber incorporado na ação. A dialética do controle, por sua vez, diz respeito ao caráter inerentemente bilateral do poder como forma de controle, e diz respeito à capacidade de os menos poderosos administrarem recursos a fim de lograrem exercer o controle sobre os mais poderosos em relações estabelecidas de poder. 
pois o movimento serviu como recurso de visibilidade acerca do que ocorria no presídio (por exemplo, através da mobilização da imprensa), bem como foi decisivo na argumentação com a polícia (GALLI, 2013).

Ainda pesava, para os gestores prisionais, outro fator: dois anos antes da entrada da ONG na prisão, a CPI do Sistema Carcerário havia considerado o PCPA como o pior presídio do Brasil. A pecha resultou no encaminhamento de uma representação à Comissão Interamericana de Direitos Humanos da OEA sobre as condições da unidade, e vinha sendo objeto de contestações pela administração, que buscava afastá-la incessantemente. $\mathrm{O}$ fato de a mudança ter se acelerado logo após uma das travestis que encabeçava as reivindicações ser agredida, a mando de um prefeito, com um pedaço de ferro (GALLI, 2013) expõe a necessidade de a direção - que se viu sob novos holofotes e visava contornar o apelido de "masmorra" dado pela CPI - articular uma alternativa. A galeria exclusiva, demanda que já estava sendo pautada pelas travestis presas e pelo movimento social, se adequou a tais pretensões.

Daí é que, quando a " 3 a do $\mathrm{H}$ " foi criada, também foi instrumentalizada em nome dos interesses dos policiais no Central, se transformando na "menina dos olhos" de uma instituição que, devido a um conjunto de pressões políticas expressivas naquele momento, precisava se mostrar, ao menos em algum nível, "humanizada" - necessidade paradoxal no contexto do cárcere. A tentativa de apropriação também se deu pelo Governo Estadual - o qual, no mesmo período, passou a um partido de esquerda, que assumiu a segurança pública (e o "problema da prisão") como uma de suas questões centrais, bem como se comprometeu a intensificar as políticas de gênero e identidade (o que fez, por exemplo, com a criação da Patrulha Maria da Penha, de uma Carteira de Nome Social para travestis e transexuais, da Sala Lilás e de um Grupo de Trabalho permanente voltado à diversidade de gênero).

Apesar da existência desses programas sugerissem adequação a um movimento histórico mais amplo, de maior visibilidade às questões de gênero na sociedade como um todo e de flexibilização das regras estruturais machistas e transfóbicas, Ferreira (2015, p. 115-116) aponta que criação da galeria não foi prevista por qualquer programa governamental, mas "fruto do conjunto de reivindicações de travestis presas" e da "luta histórica das travestis, organizadas fora e dentro do PCPA”. Ainda assim, a versão oficial é de que a iniciativa partiu da Superintendência dos Serviços Penitenciários do Estado (Susepe) em parceria com a Secretaria Estadual da Saúde, Secretaria da Justiça e dos Direitos Humanos (SJDH) e a ONG Igualdade - ignorando-se inteiramente a mobilização das travestis presas. 
Nos relatos de travestis do movimento social, por sua vez, surgem pontos de tensão com as travestis presas: algumas teriam resistências e desconfianças, acreditando que a ONG buscava se promover ao seu custo; outras, não desejavam interferências de fora e queriam organizar-se internamente. Uma entrevistada chegou a afirmar que a prefeitura da " 3 a do H" estaria “capenga" por não funcionar da maneira que as integrantes do movimento desejavam. De outro lado, apontam que a relação com os policiais e a direção era "100\%" e que as presas estavam sendo chamadas pelo nome social, o que demonstraria o sucesso do trabalho desenvolvido - embora visitas de campo, feitas em 2013, tenham apontado para o oposto, com os policiais se dirigindo às travestis pelo nome civil (AGuinsky; FERreira; Cipriani, 2013).

Diante da disputa de protagonismo - que também abarcou travestis falando em primeira pessoa e se intitulando as responsáveis pela ideia (FERrEIRA, 2015) - pode-se inferir que a " 3 a do $H$ " resultou não da mera concessão da galeria pela administração prisional ou puramente da conquista das travestis, mas de demandas e interesses articulados por agentes que reproduzem e, com isso, também modificam as estruturas (GIDDENs, 2013). Os significados assumidos por meio dessas práticas não necessariamente tiveram como foco principal a superação da transfobia ou a concessão de condições mais humanas para as travestis, ainda que essas razões tenham sido discursivamente mobilizadas pelos agentes do Estado.

No lugar de uma simples "sensibilidade humanitária" - explicação rechaçado por Foucault (2008) ao tratar da abolição dos suplícios - a " 3 a do $\mathrm{H}$ ” foi fruto de atos motivados, ações intencionais e consequências impremeditadas da ação que se imiscuíram por meio de diferentes atores (GIDDENS, 2013), com o espaço específico resultando de sucessivos movimentos que desencadearam contra-movimentos (Bourdieu, 2015). Enfim, percebe-se que a galeria resultou de uma "cooperação singular e situada em momento histórico preciso” (SEFfner; PAssos, 2016, p. 142), indicando que o mundo social transcende as intenções subjetivas e os projetos conscientes, e que as relações interpessoais nunca são, exceto em aparência, apenas individuais (BOURDIEU, 2013).

\section{CONSIDERAÇÕES FINAIS: MUDANÇA E REPRODUÇÃO}

Observa-se, correndo lado a lado nas dinâmicas do Central, a reprodução de regras estruturais e sua transformação. A criação da " 3 a do H" não foi necessariamente resultante de uma "revolta subversiva que conduz à inversão das categorias de percepção e de avaliação" (BouRdieu, 2010, p. 144), e a estrutura transfóbica que informava a prisão seguiu servindo de referência à ação social. Isso se percebe 
tanto pela manutenção da resistência dos policiais em chamar as travestis pelo nome social quando pela proibição, por parte da atual gestão, quanto à utilização de roupas femininas fora da galeria - sob o argumento de que se trata de uma "cadeia masculina" e de que tal uso "afronta perigosamente as questões de segurança, notadamente por causar a comoção no restante da massa carcerária”.

Paralelamente, e também com base em razões que apelam à segurança e à proteção, uma das consequências do surgimento da " 3 a do H" foi dificultar as demandas por educação e geração de renda das travestis, que não poderiam participar dessas atividades, pois “aparentemente sofreriam preconceito de outros presos ao entrarem em contato com estes” (FERrEIRA, 2015, p. 126). Nesse sentido, ao mesmo tempo em que carregava o potencial de flexibilizar as regras sociais referentes ao gênero e à identidade na prisão, ensejando melhor tratamento das travestis pela polícia e uma verdadeira guinada em direção à sua "humanização" e acesso à "cidadania" - sempre entre aspas - a exclusão proporcionada pela galeria passou a reforçar as demais condições estruturais que acompanham a existência dessa população.

A evasão escolar, a baixa escolaridade e o despreparo técnico e profissional estão consideravelmente presentes na vida das travestis (NAVAS, 2011), consoante indicado pelo relatório ${ }^{10}$ publicado no ano de 2018 pela Associação Nacional de Travestis e Transexuais (ANTRA) - que estimou que, em média, 90\% das mulheres transgênero utiliza a prostituição como fonte de renda, o que resultaria da dificuldade de sua inserção no mercado formal de trabalho e da deficiência na qualificação profissional, causada pela exclusão social, familiar e escolar. Como resultado da privação de recursos - para que, quando libertas, possam transformar sua situação, a tendência é que seu baixo capital cultural e econômico siga se reproduzindo (BouRdieu, 2015), assim como sua condição pobreza, por intermédio do que Giddens (2013) chama de "laços causais homeostáticos"11.

De outra banda, no cotidiano da " 3 a do $\mathrm{H}$ ", as travestis seguiram reproduzindo práticas sociais consideradas subalternas naquele contexto. Segundo Ferreira (2018), tanto elas quanto os homossexuais possuem papel importante na manutenção de um sistema binário que se fundamenta, dentre outras coisas, no

9 Como consta em ofício encaminhado pelo diretor do Central em junho de 2019, em resposta a relatório da Comissão Especial para Análise da Violência Contra a População LGBT da Assembleia Legislativa do estado.

$10 \mathrm{O}$ documento pode ser acessado no seguinte endereço: https://antrabrasil.files.wordpress. com/2018/02/relatc3b3rio-mapa-dos-assassinatos-2017-antra.pdf

11 Consoante Giddens (2013), laços homeostáticos são fatores causais que possuem um efeito de feedback na reprodução do sistema - o que ocorre, nesses casos, de forma praticamente mecânica. 
estabelecimento de lugares próprios ao masculino e ao feminino - com o primeiro representando o mando e o segundo a sujeição. Assim, conforme já havia sido sinalizado, a noção de dominação simbólica (Bourdieu, 2010) permaneceu pautando as relações na galeria específica, com os dominados aplicando a si mesmos as categorias de avaliação dos dominantes - por exemplo, com a reprodução, nos casais, de tradicionais divisões de papéis masculinos e femininos (FERREIRA, 2018).

Paralelamente, a representação da galeria - a prefeitura - passou a ser atribuída à travesti com melhor capacidade de absorver o discurso do movimento social sobre como essa população deve agir no cárcere: incorporando o projeto da ONG, não agredindo outras presas, não sendo usuária de drogas, vestindo-se bem durante reportagens e reproduzindo, na prática, "os ditames de como as travestis devem ou não se comportar na frente das câmeras e da mídia de um modo geral” (FERreIrA, 2015, p. 145-146). Ainda que tais pretensões possam ter sido orientadas pela tentativa de transformar os esquemas de percepção que encaram as travestis como seres perigosos e "pessoas afeitas ao crime" (SERRA, 2018), também atuaram para restringir a manifestação da agência das travestis presas, tornando-as oprimidas em um local que deveria ser seu (FERREIRA, 2015).

Todavia, é preciso reconhecer que o conjunto de abusos físicos e sexuais que eram reiteradamente causados às travestis por parte de demais apenados cessaram, o que contribuiu expressivamente para uma melhor condição de vida no espaço carcerário. Ademais, se o eventual assassinato de uma travesti no cárcere era até a sua união, organização política e pressão constante, gerando um "incômodo" na gestão - um evento praticamente invisível, tal realidade foi alterada drasticamente (Seffner; PAssos, 2016). A emergência da " 3 a do H" fez com que as normas da vida coletiva das travestis passassem a ser estabelecidas por elas próprias, extinguindo-se os rituais de humilhação, escárnio e deboche protagonizados por prefeitos das galerias onde elas outrora se encontravam. Portanto, embora sujeitas a certos enquadramentos, as travestis também assumiram posições para o exercício da agência a que jamais teriam acesso em outro cenário que não o da galeria exclusiva (SouzA; FERrEIRA, 2016).

Não houve com a ala específica, entretanto, transformação estrutural radical posto que nem a viabilização de direitos concretos repercutiu em reconhecimento social por parte dos demais presos e agentes prisionais, nem a separação rompeu com as regras sociais calcadas no gênero que estavam presentes anteriormente, as quais apenas assumiram outros formatos. Além disso, o que se pode inferir é que, ao mesmo tempo em que adquiriram autonomia para instaurar seu espaço e determina-lo, as travestis se configuraram como agentes "perfeitamente 'sinto- 
nizados' com o regimento disciplinar da penitenciária - constituindo a Ala que menos apresenta problemas para os dirigentes da instituição" (Silva; Seffrner, 2013, p. 05). Em paralelo, com os discursos advindos do movimento social - cujas integrantes afirmavam, naquele período, ter melhor relação com os policiais do que com as travestis presas.

Percebe-se, assim, tanto que a existência de fissuras nas estruturas sociais possibilita o advento da agência - a qual articula eventos que as provocam a se movimentar - quanto que esse trânsito pode se dar pelo acomodamento da estrutura, reproduzida e transformada em um só tempo (GIDDENs, 2013). Dessa forma, a agência se encontra estruturalmente condicionada por fatores históricos, porque a estrutura sempre representa um contexto espacial e temporal. As noções de ação e de estrutura, como visto, se pressupõem uma à outra, através de uma relação do tipo dialético, já que existe espaço para o potencial transformador das práticas sociais, mas elas sempre são atividades situadas (GidDENs, 2000). Em outras palavras, consoante sintetizado por Ortner (2006), ainda que a história efetivamente "faça" as pessoas, são as próprias pessoas que fazem a história.

No âmbito do debate aqui proposto, ainda é necessário apontar que a própria existência travesti abre espaço para uma reflexão sobre o peso das estruturas e a viabilidade da agência dos atores na constituição dos fenômenos sociais, bem como na reprodução ou na ruptura da ordem social. A transfobia é uma dimensão estrutural das relações sociais que decorre da organização social do sexo/gênero no contexto de nossos regimes de poder. Para Butler (2017), a norma binária que estabelece as linhas culturais entre o homem/masculino e a mulher/feminino visa à estabilidade entre o que toma como opostos complementares, que é possibilitada pela heterossexualidade compulsória - onde o casal heterossexual não só é pressuposto, mas essencial para a manutenção (e reprodução) normativa (BuTLER, 2017).

Dentro dessa configuração, identidades nas quais o gênero não decorre do sexo, ou em que o desejo não decorre nem do gênero, nem do sexo, são invisibilizadas e rechaçadas - o que assenta a abjeção de suas vidas, que são tomadas como não importantes, e de suas existências, não reconhecidas ou legitimadas nas dinâmicas sociais (BUTLER, 2006). Por isso, as reações violentas às travestis decorrem da própria força da norma binária de gênero e do peso que adquire como propriedade das estruturas - sendo atualizada, a cada momento, como dada e não como construída e imposta, mantendo-se seu caráter de neutralidade. A identidade travesti, imersa em regras sociais que reproduzem o cisgênero como norma hegemônica, demonstra que a sociedade não dá conta de determinar, holisticamente, as existências individuais. Assim, a experiência de vida dessas pessoas é, em si mesma, 
uma forma de resistência, pois desestabiliza a norma sexo-gênero que permeia as regras estruturais coletivamente partilhadas.

\section{REFERÊNCIAS BIBLIOGRÁFICAS}

Aguinsky, Beatriz Gerherson; Ferreira, Guilherme Gomes; Cipriani, Marcelli. A carteira de nome social para travestis e transexuais no Rio Grande do Sul: entre polêmicas, alcances e limites. In: Anais eletrônicos do Seminário Internacional Fazendo Gênero 10 - Desafios atuais dos feminismos. Florianópolis, 2013.

Alexander, Jeffrey Charles. O novo movimento teórico. Revista brasileira de Ciências Sociais, v.2, n.4, jun., 1987.

BARreto, Victor Hugo de Souza Barreto. A pesquisa em práticas sexuais: políticas e moralidades na academia. Revista Antropolítica, n. 43, v. 2, p. 203-229, 2017.

Bourdieu, Pierre. A dominação masculina. 8 ed. Rio de Janeiro: Bertrand Brasil, 2010. . A economia das trocas simbólicas. 8 ed. São Paulo: Perspectiva, 2015. Outline of a theory of practice. 28th printing. Cambridge: Cambridge University Press, 2013.

BRASIL. Ministério da Justiça e Segurança Pública. Departamento Penitenciário Nacional. Levantamento Nacional de Informações Penitenciarias: INFOPEN Atualização Junho de 2016. Brasília, 2017a.

Ministério da Justiça e Segurança Pública. Departamento Penitenciário Nacional. Levantamento Nacional de Informações Penitenciarias: INFOPEN Mulheres. 2 ed. Brasília, 2017b.

ButLer, Judith. Problemas de gênero: feminismo e subversão da identidade. 4. ed. Rio de Janeiro: Civilização Brasileira, 2017.

Vida precaria: el poder del duelo y la violencia. Buenos Aires: Paidós, 2006.

CAmpos, Marcelo da Silveira. Pela metade: as principais implicações da nova lei de drogas no sistema de justiça criminal em São Paulo. Tese (Doutorado em Sociologia). Faculdade de Filosofia, Letras e Ciências Humanas da Universidade de São Paulo, São Paulo, 2015.

CARrara, Sérgio; Vianna, Adriana de Resende Barreto. “Tá lá o corpo estendido no chão...”: a Violência Letal contra Travestis no Município do Rio de Janeiro. PHYSIS, v. 16, n. 2, p. 233-249, 2006.

CIPRIANI, Marcelli. Os coletivos criminais de Porto Alegre entre a "paz" na prisão e a guerra na rua. Dissertação (Mestrado em Ciências Sociais). Programa de Pós-Graduação em Ciências Sociais da Pontifícia Universidade Católica do Rio Grande do Sul, Porto Alegre, 2019. 
Ferreira, Guilherme Gomes. Donas de rua, vidas lixadas: interseccionalidades e marcadores sociais nas experiências de travestis com o crime e o castigo. Tese (Doutorado em Serviço Social). Programa de Pós-Graduação em Serviço Social da Pontifícia Universidade Católica do Rio Grande do Sul, Porto Alegre, 2018.

.Travestis e prisões: experiência social e mecanismos particulares de encarceramento no Brasil. Curitiba: Multideia, 2015.

.Violência, interseccionalidades e seletividade penal na experiência de travestis presas. Temporalis: Revista da Associação Brasileira de Ensino e Pesquisa em Serviço Social, v. 14, n. 27, p. 99-117, 2014.

Foucault, Michel. Microfísica do poder. São Paulo: Edições Graal, 2011.

. Vigiar e punir: nascimento da prisão. Petrópolis: Vozes, 2008.

GaLli, Gabriel. Dignidade entre grades. Revista Experiências, p. 06-10. 2013.

GidDEns, Anthony. A constituição da sociedade. 3 ed. São Paulo: Editora WMF Martins Fontes, 2013.

. Central Problems in Social Theory: action, structure and contradiction in social analysis. London: Macmillan Education LTD, 1979.

Dualidade da estrutura: agência e estrutura. Oeiras: Celta Editora, 2000.

Godor, Rafael. Fluxos em cadeia: as prisões em São Paulo na virada dos tempos. São Paulo: Boitempo, 2017.

GóEs, Eda Maria. A recusa das grades: rebeliões nos presídios paulistas: 1982-1986. São Paulo: IBCCRIM, 2009.

Kulıck, Dom. Travesti: prostituição, sexo, gênero e cultura no Brasil. Rio de Janeiro: Editora Fiocruz, 2008.

LAGo, Natália; Zamboni, Marcio. Políticas sexuais e afetivas da prisão: gênero e sexualidade em contextos de privação de liberdade. Anais do 400 Encontro Anual da ANPOCS, SPG 13 - Estudos em Antropologia do Direito, Sociologia da Punição e encarceramento. Caxambu-MG, 2016.

Lourenço, Luiz Claudio; Alvarez, Marcos César. Estudos sobre prisão: um balanço do estado da arte nas ciências sociais nos últimos vinte anos no Brasil (1997-2017). BIB, V.2, N. 84, P. 216-236, 2017.

NAvas, Kleber de Mascarenhas. Travestilidades: trajetórias de vida, lutas e resistências de travestis como construção de sociabilidade. Dissertação (Mestrado em Serviço Social). Faculdade de Serviço Social da Pontifícia Universidade Católica de São Paulo. São Paulo, 2011.

Ortner, Sherry. "Uma atualização da teoria da prática". In: Grossi, Miriam Pillar et al (Orgs.) Conferências e práticas antropológicas, 25a Reunião Brasileira de Antropologia. Blumenau: Nova Letra, 2006, p. 19-44. 
PAssos, Amilton Gustavo da Silva. Uma ala para travestis, gays e seus maridos: pedagogias institucionais da sobrevivência no Presídio Central de Porto Alegre. Dissertação (Mestrado em Educação). Faculdade de Educação da Universidade Federal do Rio Grande do Sul, Porto Alegre, 2014.

Ramalho, José Ricardo. Mundo do crime: a ordem pelo avesso [online]. Rio de Janeiro: Centro Edelstein de Pesquisas Sociais, 2008.

Silva, Rosimeri Aquino da; Seffner, Fernando. A ala LGBT do Presídio Central de Porto Alegre. In: Anais eletrônicos do Seminário Internacional Fazendo Gênero 10 Desafios atuais dos feminismos. Florianópolis-SC, 2013.

SEFfner, Fernando; PAssos, Amilton Gustavo da Silva. Uma galeria para travestis, gays e seus maridos: forças discursivas na geração de um acontecimento prisional. Sexualidad, Salud y Sociedad, n. 23, p. 140-161, 2016.

SERRA, Victor Siqueira. "Pessoa afeita ao crime”: criminalização de travestis e o discurso judicial criminal paulista. Dissertação (Mestrado em Direito). Faculdade de Ciências Humanas e Sociais da Universidade Estadual Paulista Júlio de Mesquita Filho. França, 2018.

SouzA, Bruna Caldieraro; FERreira, Guilherme Gomes. Execução penal e população de travestis e mulheres transexuais: o caso do Presídio Central de Porto Alegre. Cadernos de Gênero e Diversidade, v. 2, p. 26-35, 2016

Sykes, Gresham. The Society of Captives: A Study of a Maximum Security Prison. Princeton: Princeton University Press, 1958.

Welzer-Lang, Daniel. A construção do masculino: dominação das mulheres e homofobia. Estudos Feministas, Florianópolis, ano 9, p. 461- 482, 2001.

Zaluar, Alba. Da revolta ao crime S.A. São Paulo: moderna, 1996.

Zamboni, Marcio. Travestis e Transexuais Privadas de Liberdade: a (des)construção de um sujeito de direitos. Revista Euroamericana de Antropologia, v. 5, n. 2, jun., p. 15-23, 2016.

O barraco das monas na cadeia dos coisas: notas etnográficas sobre a diversidade sexual e de gênero no sistema penitenciário. ARACE - Direitos Humanos em Revista, ano 4, n. 5, p. 93-115. 2017. 